\title{
Temporal variability in chlorophyll $a$ and phaeopigment concentrations during incubations in the absence of grazers*
}

\author{
Satoru Taguchi**, Edward A. Laws, Robert R. Bidigare \\ Department of Oceanography, University of Hawaii at Manoa, 1000 Pope Road, Honolulu, Hawaii 96822, USA
}

\begin{abstract}
Changes in chlorophyll $a$ (chl a) and phaeopigment concentrations during $24 \mathrm{~h}$ incubations in water prefiltered through $2.0 \mu \mathrm{m}$ Nuclepore filters were determined on a weekly basis over a period of 13 mo using water from Kaneohe Bay, a subtropical inlet in the Hawaiian Islands, USA. In bottles illuminated at a constant irradiance of $4.0 \mathrm{E} \mathrm{m}^{-2} \mathrm{~h}^{-1}$, both chl a and phaeopigment concentrations were consistently lower than initial values at the end of the incubations. Chl a concentrations declined at a lower rate in dark bottles than in light bottles. There was no evidence of a change in phaeopigment concentrations in dark bottles. There was no temporal pattern in the exponential decay rates of phaeopigments in light bottles over the course of the 13 mo study, the median value being $0.016 \mathrm{~m}^{2} \mathrm{E}^{-1}$ There was, however, evidence of a nonrandom temporal pattern in the chl a decay constants. Winter values were about twice as large as summer values, a result presumably reflecting changes in the physiology and/or species composition of the phytoplankton community. In about $30 \%$ of the incubations phaeopigment concentrations were higher than initial values at intermediate time points, in some cases by as much as a factor of 2 to 3 during the first 4 to 8 h of the incubations. These results are believed to have been caused by stress associated with the effort to remove grazers by filtration. Inclusion of nanoplankton $(2$ to $10 \mu \mathrm{m})$ in the incubation bottles consistently resulted in a higher concentration of phaeopigments in the picoplankton fraction after $24 \mathrm{~h}$ than was the case in control bottles containing only picoplankton. In this study as in other work, prescreening through $10 \mu \mathrm{m}$ filters appeared to be insufficient to eliminate grazing artifacts from phaeopigment photodegradation experiments. Dilution rather than filtration may be a more practical way to account for grazing effects in such studies
\end{abstract}

\section{INTRODUCTION}

Chlorophyll a (chl a) concentrations have been used for many years by biological oceanographers as a measure of phytoplankton biomass (Richards \& Thompson 1952, Shuman \& Lorenzen 1975, Taguchi \& Laws 1989), and both phytoplankton growth rates and zooplankton grazing rates have been calculated from changes in chl a concentrations over time (Landry \& Hassett 1982). Certain chl a degradation products, namely phaeophorbide $a$ and phaeophytin $a$, are

- School of Ocean and Earth Science and Technology contribution No. 3276

- Present address: Hokkaido National Fisheries Research Institute, 116, Katsurakoi, Kushiro, Hokkaido 085, Japan indicators of grazing activity (Jeffrey 1980). The potential use of these phaeopigments to study feeding relationships began to attract attention during the $1960 \mathrm{~s}$ (Currie 1962, Nemoto 1968) and was explored quantitatively in subsequent years (Shuman \& Lorenzen 1975, Welschmeyer \& Lorenzen 1985, Wang \& Conover 1986, Laws et al. 1988). There is no doubt that phaeopigments are commonly produced by a wide variety of zooplankton, including copepods, euphausids, salps, and phagotrophic flagellates (Nemoto 1968, Jeffrey 1980, Stoecker 1984, Parslow et al. 1986, Sherr et al. 1986, Dryden \& Wright 1987). The fecal material excreted by these organisms has a considerable range of sinking rates, from almost negligible values (Small et al. 1987) to about $100 \mathrm{~m} \mathrm{~d}^{-1}$ (Lorenzen et al. 1983). Phaeopigments packed in fecal pellets with rapid sink- 
ing rates are soon lost from the euphotic zone; those ejected in loose aggregates with low sinking rates may remain for a considerable period of time (Small et al. 1987). The spatial distribution of phaeopigments has been well documented, and their dissimilar distribution to chl a has often been reported (i.e. Lorenzen 1967). Those observations reflect the fact that different processes control the gain and loss of chl a and phaeopigments in the euphotic zone.

The production of phaeopigments by grazers has proven to be a controversial subject, the calculated molar conversion efficiencies of chl a to phaeopigments ranging from virtually zero to $100 \%$ (Shuman \& Lorenzen 1975, Conover et al. 1986, Hendry et al. 1987). Factors which affect the production and fate of suspended phaeopigments in the euphotic zone include: (1) the accumulation of phaeopigments within phytoplankton cells during adverse growth conditions (Hendry et al. 1987); (2) the release of phaeopigments in fecal material by micrograzers (Stoecker 1984); (3) the loss of phaeopigments due to coprophagy by microzooplankton and other groups of filter-feeders (Hofman et al. 1981, Burkhill et al. 1986, Klein et al. 1986. Hendry et al. 1987); (4) the disappearance of phaeopigments due to photodegradation (SooHoo \& Kiefer 1982a); and (5) the loss of phaeopigments due to enzymatic reactions (Hendry et al. 1987). The variety of processes which can alter the concentration of phaeopigments tends to confound any simple mechanistic interpretation of changes in their concentrations. When phaeopigments are assayed by fluorimetric methods (Strickland \& Parsons 1972), the meaning of the results may be further confounded by the tendency of chl $b$ to cause a systematic overestimation of the phaeopigment concentration (Loftus \& Carpenter 1971, Gibbs 1979, Lorenzen \& Jeffrey 1980, Trees et al. 1985, Vernet \& Lorenzen 1987).

Most phaeopigment studies have been concerned with mechanisms which produce phaeopigments. Relatively little attention has been devoted to a systematic study of the fate of suspended phaeopigments, the principal exception being the study of photodegradative processes (Moreth \& Yentsch 1970, SooHoo \& Kiefer 1982a, Welschmeyer \& Lorenzen 1985, Klein et al. 1986) The results of these studies have not always led to consistent conclusions. For example, SooHoo \& Kiefer (1982b) and Welschmeyer \& Lorenzen (1985) suggested that photodegradation of phaeopigments was iemperature-dependent and temperature-independent, respectively. The latter authors concluded that a single estimate of the photodegradation constant could be applied to a temperate fjord and the north central and south central Pacific gyres. The same photodegradation constant has been assumed in several other studies (Marra et al. 1987, Litaker et al. 1988).
The purpose of the work reported here was to try to resolve some of the discrepancies in reported phaeopigment photodegradation characteristics or at least to identify factors responsible for the discrepancies. Specifically, we examined (1) the adequacy of prescreening through 10 and $2 \mu \mathrm{m}$ Nuclepore filters to eliminate grazing artifacts, (2) temporal variability in the decay constants associated with photodegradation of chl $a$ and phaeopigments, and (3) evidence for the accumulation and/or disappearance of phaeopigments during dark incubations. The null hypotheses were that prescreening eliminated grazing effects, there was no temporal variability in photodegradation constants, and there was no degradation of phaeopigments in the dark. Our results are based on a total of 48 experiments conducted over a period of $1 \mathrm{yr}$ in Kaneohe Bay, a subtropical inlet on the island of Oahu, (Hawaii, USA).

\section{MATERIALS AND METHODS}

Water samples were collected at approximately 09:00 h from a location in the southeast sector of Kaneohe Bay $\left(21^{\circ} 25.4^{\prime} \mathrm{N}, 157^{\circ} 47.2^{\prime} \mathrm{W}\right)$ on a weekly basis from December 10, 1986 to December 29, 1987 The water column at the station was about $10 \mathrm{~m}$ deep Samples were collected by submerging a polypropylene screw-cap bottle to a depth of approximately $10 \mathrm{~cm}$. The screw cap was not removed until the bottle was submerged in order to avoid contamination from surface films. Photosynthetically active radiation (PAR) was recorded continuously on the day prior to sample collection with a LI-COR Model LI 1905B light meter located on the roof of the Hawaii Institute of Marine Biology, $1.5 \mathrm{~km}$ from the sampling location. Surface temperature was measured to the nearest $0.1^{\circ} \mathrm{C}$ with a mercury thermometer. The water samples were sequentially filtered through 10,2 , and $0.2 \mu \mathrm{m}$ Nuclepore filters, with frequent filter changes to avoid clogging and possible damage of cells (Furnas 1987). The filters were analyzed for chl $a$ and phaeopigments on a Turner fluorometer using procedures recommended by Holm-Hansen et al. (1965). The Nuclepore filter-induced increase in background fluorescence was subtracted from the readings (Venrick 1987). which were taken between 40 and 80 units on scale, at the maximum sensitivicy setting of the fluorometer. We will henceforth refer to the $0.2-2,2-10$ and $>10 \mu \mathrm{m}$ fractions as the picoplankton, nanoplankton, and microplankton, respectively, although it is customary to use $20 \mu \mathrm{m}$ as the division between the latter 2 categories (Sieburth et al. 1978)

Aliquots of the $2 \mu \mathrm{m}$ filtrate were transfered to acidcleaned $500 \mathrm{ml}$ polycarbonate light or dark bottles and 
incubated for $24 \mathrm{~h}$ at a temperature of $24^{\circ} \mathrm{C}$ and irradiance of $4 \mathrm{E} \mathrm{m}^{-2} \mathrm{~h}^{-1}$. The incubation temperature was chosen to be the annual average observed in situ (Taguchi \& Laws 1987) and was maintained within $0.1^{\circ} \mathrm{C}$ with the use of a temperature-controlled incubator. Artificial light was provided by an ORCON xenon lamp Model 1000 with PAR spectral characteristics similar to those of natural sunlight (air mass $=1$ ). The level of irradiance was set close to the median value of highest hourly PAR based on daily records kept over the course of a year. The light level in the incubation bottle was determined for each experiment with a Biospherical Instruments Model QSL 100 scalar quantum sensor. At the beginning of the incubation, at $24 \mathrm{~h}$ and at 1 to 3 intermediate time points, duplicate subsamples were withdrawn from the bottles, filtered, and analyzed for chl $a$ and phaeopigments as previously described. On 5 occasions parallel experiments were conducted with 10 and $2 \mu \mathrm{m}$ filtrate to check for the possible effects of micrograzers in the $2-10 \mu \mathrm{m}$ fraction.

Pigment concentrations were fit to the following equation to estimate the degradation constant $k$ :

$$
P_{t}=P_{0} \mathrm{e}^{-k t}
$$

where $P_{0}$ and $P_{t}$ are the pigment concentrations (mg $\mathrm{m}^{-3}$ ) at the beginning of the incubation and at time $t$ later, respectively. The following equation was employed to isolate changes in pigment concentrations associated with light effects:

$$
P_{t}=P_{\mathrm{d}} \mathrm{e}^{-k^{\prime} t}
$$

where $P_{d}$ is the pigment concentration $\left(\mathrm{mg} \mathrm{m}^{-3}\right)$ in a dark bottle at time $t$, and $k^{\prime}$ is the degradation constant corrected with values in dark bottles.

In order to check for possible artifacts in our phaeopigment estimates caused by chl $b$, we collected a total of 17 samples from the same station on a weekly basis during May-September, 1990, and analyzed them for pigment concentrations both with our Turner fluorometer and with a high-pressure liquid chromatography (HPLC) system (Bidigare et al. 1989). The chl $b$ concentrations obtained from the HPLC analysis were then used to estimate the probable error in our fluorimetrically determined phaeopigment concentrations (Vernet \& Lorenzen 1987).

\section{RESULTS}

The results of the 1990 study to estimate the error in the fluorimetric phaeopigment concentrations caused by the presence of chl $b$ are summarized in Table 1 .
Table 1. Summary of results of pigment analyses carried out by fluorimetry and HPLC on 17 occasions between Dec 31 , 1990 and Sep 19, 1990. Concentration units are $\mu \mathrm{g} \mathrm{m}^{-3}$ \pm standard deviation

\begin{tabular}{|lc|}
\hline Pigment & Concentration \\
\hline Chl $a$ & $822 \pm 265$ \\
Chl $b$ & $34 \pm 23$ \\
Phaeopigments & $353 \pm 115$ \\
\hline
\end{tabular}

The chl $a / \mathrm{chl} b$ and phaeopigment/chl $b$ ratios averaged about 25 and 10, respectively. The overestimate of phaeopigment concentrations caused by chl $b$ in the fluorimetric technique has been estimated to be anywhere from 1.0 to 2.5 times the chl $b$ concentration (Vernet \& Lorenzen 1987). Given the mean chl $b$ concentration of $34 \mu \mathrm{g} \mathrm{m}^{-3}$, this overestimate would amount to 34 to $85 \mu \mathrm{g} \mathrm{m}^{-3}$, or 10 to $24 \%$ of the mean fluorimetrically determined phaeopigment concentration. Based on these results, it is probably fair to say that our fluorimetrically determined phaeopigment concentrations were not overestimated by more than $17 \pm 7 \%$.

Most of the chl $a$ and phaeopigments were found in the picoplankton and nanoplankton fractions. Together these 2 fractions accounted for $79 \pm 4 \%$ (mean $\pm 95 \%$ confidence limits) and $89 \pm 3 \%$ of the chl $a$ and phaeopigments, respectively, in our samples. About half of the chl $a$ and phaeopigments were found in the picoplankton fraction, $52 \pm 4 \%$ and $47 \pm 4 \%$, respectively.

Removing nanoplankton had no effect on picoplankton phaeopigment concentrations during the first $15 \mathrm{~h}$ of the incubations, but picoplankton phaeopigment concentrations were consistently higher in bottles containing nanoplankton at time points between 18 and $24 \mathrm{~h}$ (Fig. 1). Phaeopigment concentrations in light bottles were lower than initial concentrations at the end of $24 \mathrm{~h}$ in all 48 experiments (Fig. 2), a result consistent with the expected effects of photodegradation. However, phaeopigment concentrations were actually higher than initial concentrations at one or more intermediate time points in 14 of the light bottle experiments (Fig. 2). Those 14 experiments clearly show that the change of phaeopigment concentration with time is not always well described by Eq. (1). Concentrations of phaeopigments at the end of $24 \mathrm{~h}$ in dark bottles were not significantly different from initial concentrations (paired $t$-test, $p>0.1$ ), but differed by less than $10 \%$ of initial concentrations in only 8 experiments. In the other 40 dark-bottle experiments phaeopigment concentrations had increased by more than $10 \%$ of initial values in 16 cases and decreased in 24 cases. 


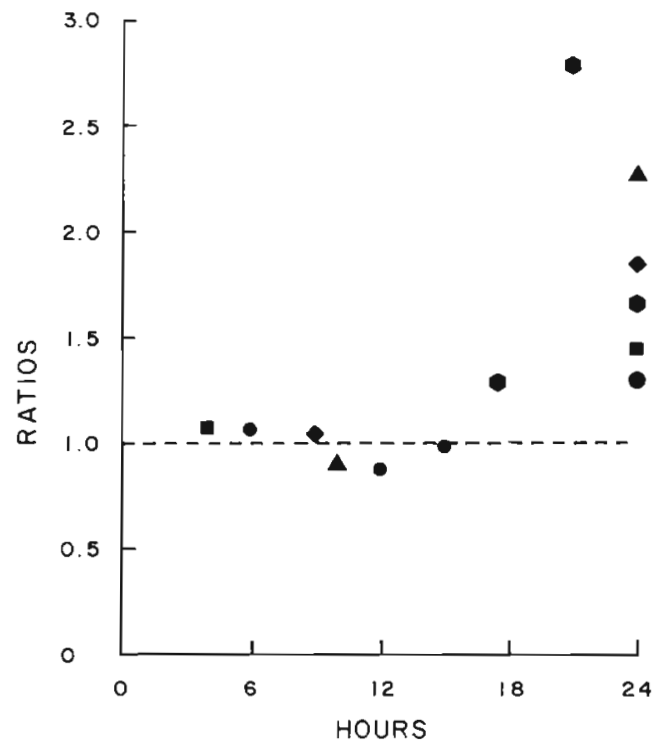

Fig. 1. Ratios of picoplankton-size phaeopigment concentrations in the presence of nanoplankton to picoplankton-size phaeopigment concentrations in the absence of nanoplankton versus incubation time. ( Dec 5, 1986; (A) Dec 29, 1986, (•) Jan 26,1987; (•) Feb 23, 1987; (ロ) Sep 22, 1987

Figs. 3 \& 4 show the temporal variabilities of PAR and the degradation constant $k$ for chl $a$ in light bottles. Table 2 summarizes median values of the estimates of $k$ and $k^{\prime}$. The data were analyzed for temporal variability based on the number of runs above and below the median value (Sokal \& Rohlf 1969). When the runs test indicated temporal variability significant at $p<0.05$, the data were further analyzed for seasonal effects using a Kruskal-Wallis (KW) test.

There was no evidence of temporal variability in the phaeopigment degradation constants $k$ and $k^{\prime}(p>0.05)$, nor was there evidence of a significant difference between $k$ and $k^{\prime}$ values (paired $t$-test, $p>0.10$ ). The median $k$ and $k^{\prime}$ values were both $0.064 \mathrm{~h}^{-1}$ (Table 2). Both numbers were significantly different from zero at $p<0.01$ (Tate \& Clelland 1957). Phaeopigment loss rates in the dark were not significantly different from zero, a result consistent with the assumption that degradation of phaeopigments is primarily the result of photochemical processes (SooHoo \& Kiefer 1982b).

$\mathrm{Chl}$ a concentrations declined in both light and dark bottles, the median $k$ values being 0.071 and $0.029 \mathrm{~h}^{-1}$, respectively. Both values were significantly different from zero at $\mathrm{p}<0.05$ (Table 2). The light $k$ values were significantly different from the dark $k$ values based on a paired $t$-test $(p<0.05)$. There was no evidence of temporal variability in the dark $k$ values, but the runs test revealed temporal variability in the light $k$ values significant at $p=0.05$. The KW test revealed a significant seasonality in the light $k$ values $(p<0.025)$, with

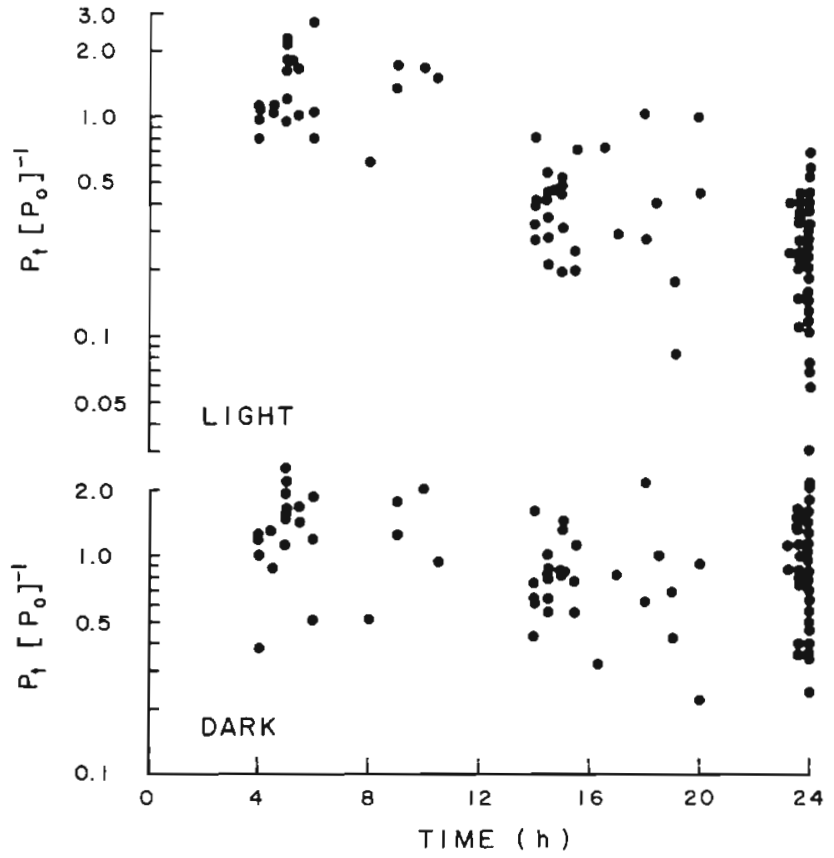

Fig. 2. Ratios of phaeopigment concentrations to phaeopigment concentrations at start of incubations in light and dark bottles

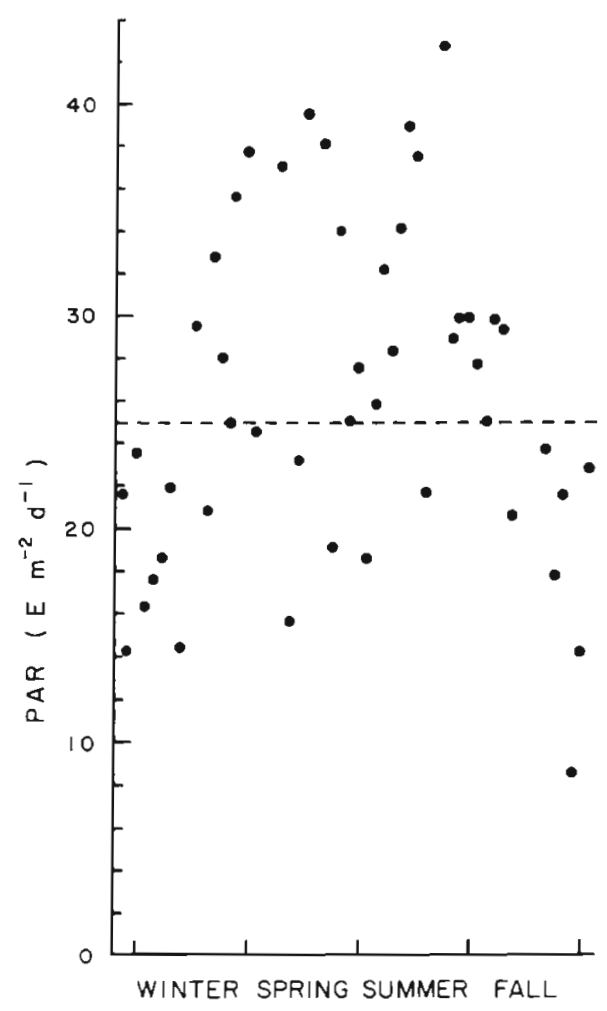

Fig. 3. Photosynthetically active radiation (PAR) in Kaneohe Bay observed on the day preceding weekly incubation experiments from December 1986 to December 1987. Dashed line indicates the median value of $25 \mathrm{E} \mathrm{m}^{-2} \mathrm{~d}^{-1}$ 


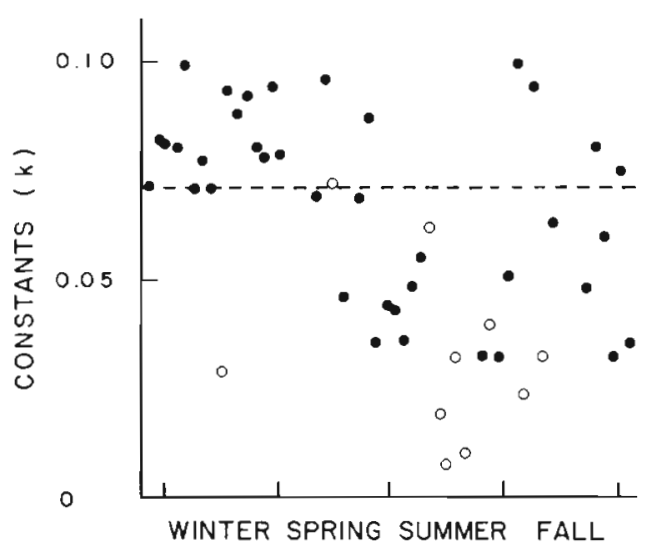

Fig. 4. Slopes $(k)$ of semilog plots of chl a versus time in light bottles from December 1986 to December 1987. (O) Slopes which were not significant at $p<0.05$. Dashed line indicates the median value

summer values being half as great as winter values (Table 2). Spring and fall values were intermediate.

\section{DISCUSSION}

Landry et al. (1984) estimated that in September 1982. Chlorella sp. accounted for about $47 \%$ of the community carbon in the water column of Kaneohe Bay at a station near our study site. If this percentage were indicative of the contribution of chlorophytes to chl $a$, the error in fluorimetrically determined phaeopigment concentrations due to the presence of chl $b$ could be quite large. Assuming a chl $a / \mathrm{chl} b$ ratio of 2.2 in chlorophytes (Wood 1979), the chl $a / c h l b$ ratio of the phytoplankton community would be $2.2 / 0.47=4.7$, and phaeopigments would be overestimated by an amount equal to 21 to $53 \%$ of the chl a concentration in the water (Vernet \& Lorenzen 1987). During our 1990 studies, however, the lowest chl $a / c h l b$ ratio measured on any of the 17 sampling dates was 8 , and the median value was 25 (Table 1). The apparent discrepancy between our HPLC results and the report of Landry et al. (1984) may be due to one or more of the following considerations: (1) Landry et al. (1984) may have encountered a somewhat atypical situation ${ }^{(2)}$ the microscopic analysis used by Landry et al. (1984) may have failed to distinguish chlorophytes from other small unicellular phytoplankton; or (3) the chl $a / c h l ~ b$ ratio in Kaneohe Bay chlorophytes may be higher than 2.2, although it seems doubtful, based on the summary of Wood (1979), that the ratio would be greater than 4 . Our calculated values of $k$ and $k^{\prime}$, which are equal to the slopes of log-linear plots of phaeopigment concentrations versus time, would be biased by chl $b$ interference only if the phaeopigment/chl $b$ ratio systemati-
Table 2. Median slopes of log-linear fits of pigment concentration versus time during $24 \mathrm{~h}$ incubations. Total number of experiments was 48 . n: no. of experiments in which the slope was significantly different from zero at $p<0.05$

\begin{tabular}{|lrrr|}
\hline \multirow{2}{*}{ Pigment } & $\mathrm{n}$ & \multicolumn{2}{c|}{ Slope } \\
& & Median & $95 \%$ confidence range \\
\hline Chl $a$ & & & \\
Dark $k$ & 42 & 0.029 & $(0.025,0.035)$ \\
Light $k$ & 38 & 0.071 & $(0.055,0.080)$ \\
$\quad$ Spring & 9 & 0.069 & $(0.044,0.094)$ \\
$\quad$ Summer & 6 & 0.040 & $(0.032,0.055)$ \\
$\quad$ Fall & 10 & 0.067 & $(0.048,0.094)$ \\
$\quad$ Winter & 13 & 0.080 & $(0.071,0.092)$ \\
Phaeopigments & & & \\
Dark $k$ & 14 & 0.013 & $(-0.013,0.038)$ \\
Light $k$ & 34 & 0.064 & $(0.050,0.085)$ \\
Light $k^{\prime}$ & 36 & 0.064 & $(0.047,0.072)$ \\
\hline
\end{tabular}

cally changed during the course of the incubations. We have no direct check on the constancy of this ratio, but the results in Table 2 indicate that the phaeopigment/chl a ratio increased by about 15 and $38 \%$ after $24 \mathrm{~h}$ in our light bottle and dark bottle incubations, respectively. If the phaeopigment/chl $b$ ratios behaved in a similar manner, then the interference caused by chl $b$ would have been reduced by a factor of 1.15 and 1.38 by the end of $24 \mathrm{~h}$ in the light and dark bottles, respectively. Since the bias caused by chl $b$ appears to have been at most $24 \%$, the maximum change in the bias would have been $(0.15)(0.24)=$ 0.036 and $(0.38)(0.24)=0.091$ in the light and dark bottles, respectively. The implication is that the phaeopigment $k$ values may have been overestimated by about $0.036 / 24=0.0015 \mathrm{~h}^{-1}$ and $0.091 / 24=0.0038 \mathrm{~h}^{-1}$ in the light and dark bottles, respectively. The former figure is only about $2 \%$ of the median calculated light bottle $k$ value. The latter figure is almost $30 \%$ of the median calculated dark bottle $k$ value, and hence tends to reinforce our conclusion that the dark bottle $k$ value was not significantly different from zero.

The seasonality apparent in the light degradation constant for chl a may well reflect seasonal changes in the physiology and/or species composition of phytoplankton in Kaneohe Bay (Taguchi \& Laws 1987). The chl a content of a cell is a function of the prevailing irradiance (Falkowski 1980), the nutritional status of the cell (Laws \& Bannister 1980), cell size (Malone 1980) and species identity (Chan 1980). The chl a: carbon ratio of cells is particularly sensitive to irradiance under nutrient-saturated conditions at light intensities approaching growth-rate-saturating values (Laws $\&$ Bannister 1980). During the winter months the irradiance in Kaneohe Bay is about $20 \%$ lower than in the summer (Fig. 3), and it seems reasonable to assume 
that under winter conditions the chl a content of Kaneohe Bay phytoplankton is therefore near a maximum. Under such conditions exposure of cells to relatively bright light $\left(4 \mathrm{E} \mathrm{m}^{-2} \mathrm{~h}^{-1}\right)$ could lead to a rapid cessation of chl a synthesis. Based on the work of Falkowski $(1980,1984)$, the observed decline of chl a concentrations in our light incubation bottles probably reflects an imbalance between normal chl a turnover and gross chl a synthesis rather than an actual bleaching of pigment. Our $k$ values for chl $a$ in the light are 20 to $70 \%$ of the chl a turnover rates estimated by Grumbach et al. (1978) for Skeletonema costatum. During the summer months any decline in chl a synthesis due to incubation in bright light would presumably be minimized by the fact that the cells had been light-adapted. This rationale is consistent with the seasonality of chl a light degradation rates in Table 2 .

If confinement in the dark for 24 h may be regarded as a limiting case of transfer from bright light to dim light, then the expected consequence would be a stimulation of chl a synthesis (Falkowski 1980). This explanation probably accounts for the fact that $k$ values for $\mathrm{chl} a$ in the dark were less than half of the corresponding light values (Table 2 ). The fact that chl a concentrations consistently declined in the dark probably reflects the fact that prescreening through $2 \mu \mathrm{m}$ filters removed virtually all protozoans and zooplankton, whose excretory products would normally have provided additional nutrients for pigment production. With an adequate nutrient supply, the expected consequence of dark confinement would be a net increase of the chl a concentration (Laws \& Wong 1978).

Welschmeyer \& Lorenzen (1985) used a $10 \mu \mathrm{m}$ nylon mesh to remove as many grazers as possible while allowing suspended phaeopigments and chlorophyll to pass through the screens. We used $2 \mu \mathrm{m}$ Nuclepore filters in the present study due to the increasing evidence that some micrograzers can pass through a $10 \mu \mathrm{m}$ Nuclepore filter (Cynar et al. 1985, Goldman \& Caron 1985, Pace \& Bailiff 1987). Landry et al. (1984) noted that the heterotrophic plankton community of Kaneohe Bay at the time of their experiments was dominated by bacteria, microflagellates, dinoflagellates, and ciliated protozoans, the latter 3 having diameters of approximately 5,7 and $30 \mu \mathrm{m}$, respectively. The microflagellates and dinoflagellates could easily have passed through our $10 \mu \mathrm{m}$ filters, and the former accounted for almost $75 \%$ of the heterotrophic ciliate and microflagellate biomass estimated by Landry et al. (1984). The autotrophic community consisted almost entirely of chroococcoid cyanobacteria, Chlorella sp., and microflagellates having diameters of approximately 1,3 and $5 \mu \mathrm{m}$, respectively (Landry et al. 1984). It is apparent from this analysis that in the case of Kaneohe Bay removing organisms larger than $10 \mu \mathrm{m}$ would not be a reliable method of eliminating grazing effects in incubation bottles.

Impacts of grazing are strongly suggested by the fact that picoplankton phaeopigment concentrations were consistently higher in bottles containing nanoplankton after incubations of 18 to $24 \mathrm{~h}$ (Fig. 1). The fact that differences in phaeopigments did not become apparent until the last $6 \mathrm{~h}$ of the experiment presumably reflects the fact that some time was required for phaeopigments produced by grazing in the incubation bottles to become significant relative to the concentration of phaeopigments. The expected behavior of the ratio shown in Fig. 1 can be determined by solving the differential equations describing the rate of change of chl $a$ and phaeopigments in our incubation bottles.

$$
\begin{gathered}
\mathrm{d}(\text { chl a }) / \mathrm{d} t=-\left(g+k_{c}\right)(\text { chl a }) \\
\mathrm{d}(\text { ohaeo }) / \mathrm{d} t=f g(\text { chl } \mathrm{a})-k(\text { phaeo })
\end{gathered}
$$

where $g=$ rate at which chl $a$ is reduced by grazing; $k_{c}$ and $k=$ decay constants for chl $a$ and phaeopigments in light bottles (Table 2); phaeo = concentration of phaeopigments; and $f=$ molar conversion efficiency of chl a to phaeopigments associated with grazing. When these equations are solved, the ratio $R$ in Fig. 1 is found to be

$R=$

$1+f g\left(c h l_{0}\right)\left[1-\exp \left(-\left(k_{c}-k+g\right) t\right)\right] /\left[\left(k_{c}-k+g\right) P_{0}\right]$

where $c h I_{0}$ and $P_{0}=$ initial concentrations of chl a and phaeopigments in the bottles, respectively, If $k=k_{\mathrm{c}}+g_{1}$ $R=1+f g t\left(\mathrm{chl}_{0} / P_{0}\right)$. If $k<k_{c}+g, R$ is an increasing function of time with a negative curvature and asymptotically approaches the value $1+f g\left(c h l_{0} / P_{0}\right) /$ $\left(k_{\mathrm{c}}-k+g\right)$ as $t$ becomes large. If $k>k_{\mathrm{c}}+g, R$ is an increasing function of time with a positive curvature and becomes a positive exponential function of time in the limit of large $t$. The data in Fig. 1 are collectively inconsistent with a function having a negative curvature, and hence suggest that in these 5 cases $k$ was greater than or equal to $k_{\mathrm{c}}+g$. An approximation of $\mathrm{fg}$ can be obtained using the $c h l_{0} / P_{0}$ ratio of 2.3 (Table 1 ) and by assuming $k=k_{\mathrm{c}}+g$. The $24 \mathrm{~h}$ results in Fig. 1 then imply that $0.13<f g<0.57$. For comparison, Landry et al. (1984) estimated grazing rates on chroococcoid cyanobacteria and Chlorella sp. in Kaneohe Bay to be 0.14 and $0.67 \mathrm{~d}^{-1}$, respectively, and the grazing rate on the total phytoplankton community to be $0.35 \mathrm{~d}^{-1}$. This comparison tends to reinforce our conclusion that filtration through $10 \mu \mathrm{m}$ Nuclepore filters was rather ineffective in reducing grazing pressure.

Based on the results of Kopylov \& Moiseev (1980), SooHoo \& Kiefer (1982b) argued that phagotrophic flagellates which could pass through a $10 \mu \mathrm{m}$ Nucle- 
pore filter were bacterivorous, and that the impact of such flagellates on phaeopigment degradation constants would therefore be minimal. However, other studies have clearly indicated that phagotrophic flagellates can consume phytoplankton and produce phaeopigments (Stoecker 1984, Parslow et al. 1986, Sherr et al. 1986, Dryden \& Wright 1987). Our results combined with the work of Landry et al. (1984) indicate that defecation by small flagellates can be a significant source of phaeopigments.

Based on a limited number of experiments, both SooHoo \& Kiefer (1982b) and Welschmeyer \& Lorenzen (1985) concluded that phaeopigment concentrations decline exponentially with time in incubation bottles when organisms larger than $10 \mu \mathrm{m}$ are removed by prescreening. Although we prescreened our water through $2 \mu \mathrm{m}$ Nuclepore filters, we observed an exponential decline in phaeopigment concentrations in only 70 to $75 \%$ of our experiments. In 14 of our 48 experiments, there was an increase in phaeopigment concentrations versus initial values at one or more intermediate time points, and in 10 cases the increase amounted to a factor of 2 to 3 within the first 4 to $8 \mathrm{~h}$ of the incubations.

It seems improbable that herbivore grazing would have accounted for such large increases in phaeopigment concentrations, particularly since our $2 \mu \mathrm{m}$ Nuclepore filters should have removed virtually all herbivores. Although poor growth conditions and prolonged exposure in the dark can lead to the accumulation of phaeopigments in cells, these mechanisms also seem improbable causes of 2 - to 3 -fold increases in phaeopigments over a time period of 4 to $8 \mathrm{~h}$. The most likely mechanism would appear to be stress to the cells associated with the filtration process (Goldman \& Dennett 1985). If this explanation is correct, the fact that phaeopigment increases were observed in only a small percentage of our experiments presumably reflects differences in the sensitivity of the phytoplankton community to filtration stress as a result of changes in species composition and/or subtle differences in filtration technique.

Regardless of the mechanism, the implication of our results is that the assumption of a simple exponential decline in phaeopigments with time in photodegradation experiments may be invalid. The problem of nonexponential decay is also apparent in the work of others. For example, although SooHoo \& Kiefer (1982b) indicate that their data support the assumption of an exponential decline in phaeopigments with time due to photodegradation, the percentage of the variance accounted for by some of their least squares fits is as low as $51 \%$, and the corresponding regression slopes appear not to be significant at $p<0.05$. Time series studies and a careful examination of data can help avoid incorrect conclusions caused by experimental artifacts. We conclude from this work that filtration is in general not a satisfactory method for eliminating grazing artifacts in phaeopigment degradation experiments. A better solution to the problem would probably be a dilution approach similar to that employed by Landry \& Hassett (1982)

In order to correct insofar as possible for artifacts associated with nonphotochemical processes, we calculated an apparent photodegradation constant $k^{\prime}$ using Eq. (2). Unexpectedly this exercise did little to improve the goodness of fit to our data. The percentage of phaeopigment semilog plots lacking a slope which was significant at $95 \%$ confidence was reduced only from 29 to $25 \%$. The implication is that the mechanisms responsible for nonlinearity of the semilog plots caused random noise and/or produced effects which were not common to both the light and dark bottles.

The median of the slope obtained from the photodegradation of phaeopigments (Table 2) can be converted to the more common unit of $\mathrm{m}^{2} \mathrm{E}^{-1}$ by dividing the $k$ or $k^{\prime}$ values by the experimental irradiance of $4 \mathrm{E}$ $\mathrm{m}^{-2} \mathrm{~h}^{-1}$. The corrected median values for both $k$ and $k^{\prime}$ then become $1.6 \times 10^{-2} \mathrm{~m}^{2} \mathrm{E}^{-1}$, which is about $43 \%$ of the average obtained by SooHoo \& Kiefer (1982b) and $26 \%$ of the value reported by Welschmeyer \& Lorenzen (1985). The latter suggested that the difference between their value and that of SooHoo \& Kiefer (1982b) was due to the fact that SooHoo \& Kiefer (1982b) measured irradiance using a meter equipped with a scalar collector, whereas Welschmeyer \& Lorenzen (1985) used a meter with a cosinecorrected, flat-plate quantum sensor. Since we used a meter with a scalar collector, the roughly 2 -fold difference between our value and that of SooHoo \& Kiefer (1982b) cannot be attributed to a difference in light meters. Furthermore, since it is apparent from Fig. 1 that prescreening with a $10 \mu \mathrm{m}$ rather than $2 \mu \mathrm{m}$ Nuclepore filter resulted in a higher concentration of phaeopigments in our incubation bottles after $24 \mathrm{~h}$, the difference between our results and those of SooHoo \& Kiefer (1982b) cannot be attributed to the lack of nanozooplankton in our incubation bottles. The difference more likely reflects a combination of regional variations as noticed by SooHoo \& Kiefer (1982b) and possibly temporal variability. SooHoo \& Kiefer (1982b) reported regional variations in phaeopigment photodegradation constants amounting to about a factor of 8 , and our data show about a $50 \%$ change in $k$ or $k^{\prime}$ values over the course of a year in Kaneohe Bay.

The water column of Kaneohe Bay is well mixed most of the time due to tidal mixing and the prevailing Trade Winds (Smith et al. 1981). Almost all properties of suspended particulate matter fail to show any significant stratification of the water column. At the station 
where the present study was conducted, the amount of light penetrating the water column is rapidly attenuated by the high concentration of suspended particulate matter. The median Secchi disc reading of $4.0 \mathrm{~m}$ (95\% confidence range; 4 to $5 \mathrm{~m}$ ) during the present study (Taguchi unpubl.) implies a visible light extinction coefficient of about $0.425 \mathrm{~m}^{-1}$ (Poole \& Atkins 1929). Since the water column at our station is about $10 \mathrm{~m}$ deep and the median surface PAR about $25 \mathrm{E} \mathrm{m}^{-2}$ $\mathrm{d}^{-1}$, the average PAR in the water column, assuming a $5 \%$ loss due to surface reflectance (Kirk 1986), is $(25)(0.95)\left(1-e^{-4.25}\right) / 4.25=5.8 \mathrm{E} \mathrm{m}^{-2} \mathrm{~d}^{-1}$. Since phaeopigments are uniformly distributed within the water column, we can estimate the average phaeopigment photodegradation rate by multiplying this mean PAR value by the photodegradation rate constant of $0.016 \mathrm{~m}^{2} \mathrm{E}^{-1}$. The photodegradation loss rate estimated in this way equals $9 \% \mathrm{~d}^{-1}$, which is comparable to the washout rate of about $7 \%$ d ${ }^{1}$ estimated by Smith et al. (1981). These 2 loss rates imply a residence time of about $6 \mathrm{~d}$ for suspended phaeopigments in the southeast sector of Kaneohe Bay. However, some loss of phaeopigments undoubtedly occurs due to coprophagy (Hofmann et al. 1981, Small et al. 1987), and it is probably unrealistic to assume that phaeopigments found in the water column are associated with particles that literally do not sink (Laws et al. 1988). Hence a figure of $6 \mathrm{~d}$ is undoubtedly an upper bound on the true residence time of phaeopigments in the water column at this location in Kaneohe Bay.

Finally, both our data and the results of previous work (e.g. Venrick et al. 1977, Bienfang \& Takahashi 1983) clearly indicate that it is unrealistic to assume phytoplankton biomass to be constant in an incubation lasting more than a few hours; although such an assumption is commonly made, for example, in the calculation of photosynthesis:biomass ratios. Temporal variability of biomass must certainly be considered in $24 \mathrm{~h}$ incubations which span a normal light: dark cycle (DiTullio \& Laws 1986). Furthermore, our results indicate that biomass measurements made only at the beginning and end of a long (e.g. 24 h) incubation can give a very incomplete picture of temporal trends, a conclusion also reached by Goldman et al. (1981), Marin et al. (1986) and McClatchie \& Lewis (1986).

\section{LITERATURE CITED}

Bidigare, R. R., Schofield, O., Prézelin, B. B. (1989). Influence of zeaxanthin on quantum yield of photosynthesis of Synechococcus clone WH7803 (DC2). Mar. Ecol. Progr. Ser. 56: $177-188$

Bienfang, P. K., Takahashi, M. (1983). Ultraplankton growth rates in a subtropical ecosystem. Mar. Biol. 76(2): 203-211

Burkhill, R. H., Mantoura R. F. C., Llewellyn, C. A., Owens,
N. J. O. (1986). Microzooplankton grazing and selectivity of phytoplankton in coastal waters. Mar. Biol. 93: 581-590

Chan, A. T. (1980). Comparative physiological study of marine diatoms and dinoflagellates in relation to irradiance and cell size. II. Relationship between photosynthesis, growth, and carbon/chlorophyll a ratio. J, Phycol. 16: 428-432

Conover, R. J., Durvasula, R. D., Roy, S., Wang, R. (1986). Probable loss of chlorophyll-derived pigments during passage through the gut of zooplankton, and some of the consequences. Limnol. Oceanogr. 31:878-887

Currie, R. I. (1962). Pigments in zooplankton faeces. Nature 193: 956-957

Cynar, F. J., Estep, K. W., Sieburth, J. McN. (1985). The detection and chractarization of bacterial-sized protists in 'protist free' filtrates and their potential impact on experimental marine ecology. Microb. Ecol. 11. 281-288

DiTullio, G., Laws, E. A. (1986). Diel periodicity of nitrogen and carbon assimilation in five species of marine phytoplankton: accuracy of methodology for predicting $\mathrm{N}$ assimilation rates and N/C composition ratios. Mar. Ecol. Prog. Ser. 32: 123-132

Dryden, R. C., Wright, S. J. L. (1987). Predation of cyanobacteria by protozoa. Can. J. Microbiol. 33: 471-482

Falkowski, P. G. (1980). Light-shade adaptation in marine phytoplankton. In: Falkowski, P. G. (ed.) Primary productivity in the sea. Plenum, New York, p. 99-119

Falkowski, P. G. (1984). Kinetics of light intensity adaptation in Dunaliella tertiolecta. Photosynthetica 18: 62-68

Furnas, M. J. (1987). Effects of prescreening on productivity of size-fractionated phytoplankton. Limnol. Oceanogr. 32 $483-491$

Gibbs, C. F. (1979). Chlorophyll $b$ interference in the fluorometric determination of chlorophyll $a$ and pheopigments Aust. J. mar. Freshwat. Res. 30:597-606

Goldman, J. C., Caron, D. A. (1985). Experimental studies on an ominivorous microflagellate: implications for grazing and nutrient regeneration in the marine microbial food chain. Deep Sea Res. 32: 899-915

Goldman, J. C., Dennett, M. R. (1985). Susceptibility of some marine phytoplankton species to cell breakage during filtration and post-filtration. J. exp. mar. Biol. Ecol. 86 $47-58$

Goldman, J., Taylor, C. D., Glibert, P. M. (1981). Nonlinear time-course uptake of carbon and ammonium by marine phytoplankton. Mar. Ecol. Prog. Ser. 6: 137-149

Grumbach, K. H., Lichtenstenthaler, H. K., Erisman, K. H (1978). Incorporation of ${ }^{14} \mathrm{CO}_{2}$ in photosynthetic pigments of Chlorella pyrenoidosa. Planta 140:37-43

Hendry, G. A. F., Houghton, J. D., Brown, S. B. (1987). The degradation of chlorophyll - a biological enigma. New Phytol. 107: 255-302

Hofmann, E. E., Klinck, J. M.. Paffenhofer, G.-A. (1981). Concentrations and vertical fluxes of zooplankton fecal pellets on a continental shelf. Mar. Biol. 61: 327-335

Holm-Hansen, O., Lorenzen, C. J., Holmes, R. N., Strickland, J. D. H. (1965). Fluorometric determination of chlorophyll J. Cons perm int. Explor. Mer. 30:3-15

Jeffrey, S. W (1980). Algal pigment systems. In: Falkowski P. G. (ed.) Primary productivity in the sea. Plenum, New York, p. 33-58

Kirk, J. T O. (1986). Light and photosynthesis in aquatic ecosysterns. Cambridge Univ. Press, Cambridge

Klein, B., Gieskes, W. W. C., Kraay, G. G. (1986). Digestion of chlorophylls and carotenoids by the marine protozoan Oxyrrhis marina studied by HPLC analysis of algal pigments. J. Plankton Res. 8: 827-836 
Kopylov, A. I., Moiseev, E. S. (1980). Effects of colorless flagellates on the determination of bacterial production in seawater. Akad. Nauk SSSR Dokl. Biol. 252: 272-274

Landry, M. Haas, L. W., Fagerness, V. L. (1984). Dynamics of microbial plankton communities: experiments in Kaneohe Bay, Hawaii. Mar. Ecol. Prog. Ser. 16: 127-133

Landry, M., Hassett, R. P. (1982). Estimating the grazing impact of marine micro-zooplankton. Mar. Biol. 67: 283-288

Laws, E. A., Bannister, T. T. (1980). Nutrient- and light-limited growth of Thalassiosira fluviatilis in continuous culture, with implications for phytoplankton growth in the oceans. Limnol. Oceanogr. 25: 457-473

Laws, E. A., Bienfang, P. K., Ziemann, D. A., Conquest, L. D. (1988). Phytoplankton population dynamics and the fate of production during the spring bloom in Auke Bay, Alaska. Limnol. Oceanogr. 33: 57-65

Laws, E. A., Wong, D. C. L. (1978). Studies of carbon and nitrogen metabolism by three marine phytoplankton species in nitrate-limited continuous culture. J. Phycol. 14: 406-416

Litaker, W., Duke, C. S., Kenney, B. E., Ramus, J. (1988). Diel $\mathrm{chl} a$ and phaeopigment cycles in a shallow tidal estuary: potential role of microzooplankton grazing. Mar. Ecol. Prog. Ser. 47: 259-270

Loftus, M. E., Carpenter, J. H. (1971). A fluorometric method for determining chlorophylls $a, b$, and $c$. J. mar. Res. 29: $319-338$

Lorenzen, C. J. (1967). Vertical distribution of chlorophyll and pheopigments: Baja California. Deep Sea Res. 14: $735-745$

Lorenzen, C. L., Jeffrey, S. W. (1980). Determination of chlorophyll in seawater. Tech. Pap. mar. Sci. (U.N.E.S.C.O.) 35

Lorenzen, C. J., Welschmeyer, N. A., Copping, A. E. (1983). Particulate organic carbon flux in the subarctic Pacific. Deep Sea Res. 30: 639-643

Malone, T. C. (1980). Algal size. In: Morris, I. (ed.) The physiological ecology of phytoplankton. Univ. California Press, Berkeley, p. 433-463

Marin, V., Huntley, M. E., Frost, B. (1986). Measuring feeding rates of pelagic herbivores: analysis of experimental design and methods. Mar. Biol. 93: 49-58

Marra, J., Wiebe, P. H., Bishop, J. K. B., Stepien, C. J. (1987). Primary production and grazing in the plankton of the Panama Bight. Bull. mar. Sci. 40: 255-270

McClatchie, S., Lewis, M. R. (1986). Limitations of grazing rate equations: the case for time-series measurements. Mar. Biol. 92: 135-140

Moreth, C. M., Yentsch, C. S. (1970). The role of chlorophyllase and light in the decomposition of chlorophyll from marine phytoplankton. J. exp. mar. Biol. Ecol, 4: $238-249$

Nemoto, T. (1968). Chlorophyll pigments in the stomachs of euphausiids. J. Oceanogr. Soc. Jap. 17: 50-55

Pace, M. L., Bailiff, M. D. (1987). Evaluation of a fluorescent microsphere technique for measuring grazing rates of phagotrophic microorganims. Mar. Ecol. Prog. Ser. 40; 185-193

Parslow, J. S., Doucette, G. J., Taylor, F. J. R., Harrison, P. J. (1986). Feeding by the zooflagellate Pseudobodo sp. on the picoplanktonic prasinomonad Micromonas pusilla. Mar. Ecol. Prog. Ser. 29: 237-246

Poole, H. H., Atkins, W. R. G. (1929). Photo-electric measurements of submarine illumination through the year. J. mar. biol. Ass. U.K. 16: 297-324
Richards, F. A., Thompson, T. G. (1952). The estimation and characterization of plankton populations by pigment analyses. II. A spectrophotometric method for the estimation of plankton pigments. J mar. Res. 11: 156-172

Sherr, E. B., Sherr, B. F., Paffenhofer, G.-A. (1986). Phagotrophic protozoa as food for metazoans: a 'missing' trophic link in marine pelegic food web? Mar. microb. Fd Webs 1 : $61-80$

Shuman, F. R., Lorenzen, C. J (1975). Quantitative degradation of chlorophyll by a marine herbivore. Limnol. Oceanogr. 20: 580-586

Sieburth, J. McN., Smetacek, V., Lenz, J. (1978). Pelagic ecosystem structure: heterotrophic compartments of the plankton and their relationship to plankton size fractions. Limnol. Oceanogr. 23: 1256-1263

Small, L. E., Knauer, G. A., Teul, M. D. (1987). The role of sinking fecal pellets in stratified euphotic zones. Deep Sea Res. 34: 1705-1712

Smith, S. V., Kimmerer, W. J., Laws, E. A., Brock, R. E., Walsh, T. W. (1981). Kaneohe Bay sewage diversion experiment: perspectives on ecosystem responses to nutritional perturbation. Pacif. Sci. 35: 279-395

Sokal, R. R., Rohlf, F. J. (1969). Biometry. W. H. Freeman, San Francisco

SooHoo, J. B., Kiefer, D. A. (1982a). Vertical distribution of pheopigments. 1. A simple grazing and photooxidative scheme for small particles. Deep Sea Res. 29: 1539-1551

SooHoo, J. B., Kiefer, D. A. (1982b). Vertical distribution of pheopigments. 2. Rates of production and kinetics of photooxidation. Deep Sea Res. 29: 1553-1563

Stoecker, D. K. (1984). Particle production by planktonic ciliates. Limnol. Oceanogr. 29: 930-940

Strickland, J. D. H., Parsons, T R. (1972). A practical handbook of seawater analysis, 2nd edn. Bull. Fish. Res. Bd Can. no. 167

Taguchi, S., Laws, E. A. (1987). Patterns and causes of temporal variability in the physiological condition of the phytoplankton community in Kaneohe Bay, Hawaii. J. Plankton Res. 9: 1143-1157

Taguchi, S., Laws, E. A. (1989). Biomass and compositional characteristics of Kaneohe Bay phytoplankton inferred from regression analysis. Pacif. Sci. 43: 316-331

Tate, M. W., Clelland, R. C. (1957). Nonparametric and shortcut statistics. Interstate Printers, Danville

Trees, C. C., Kennicutt, M. C. II, Brooks, J. M. (1985). Errors associated with the standard fluorimetric determination of chlorophylls and phaeopigments. Mar. Chem. 17: 1-12

Venrick, E. L. (1987). On fluorometric determinations of filterretained pigments. Limnol. Oceanogr. 32: 492-493

Venrick, E. L., Beers, J. R., Heinbokel, J. F. (1977). Possible consequences of containing microplankton for physiological rate measurments. J. exp. mar. Biol. Ecol. 26: 55-76

Vernet, M., Lorenzen, C. J. (1987). The presence of chlorophyll $b$ and the estimation of pheopigments in marine phytoplankton. J. Plankton Res. 9: 255-265

Wang, R., Conover, R. J. (1986). Dynamics of gut pigment in the copepod Temora longicornis and the determination of in situ grazing rates. Limnol. Oceanogr. 31: 867-877

Welschmeyer, N. A., Lorenzen, C. J. (1985). Chlorophyl budgets: zooplankton razing and phytoplankton growth in a temperate fjord and the central Pacific gyres. Limnol. Oceanogr. 30: 1-21

Wood, A. M. (1979). Chlorophyll $a: b$ ratios in marine planktonic algae. J. Phycol 15: 330-332 